\title{
Pentingnya Peran Sekolah Dalam Pendidikan Politik Bagi Siswa Tentang Kajian Berita Hoax Di Indonesia
}

\author{
Kris Yunianto ${ }^{1}$, Marlina Dea $^{2}$, Dimas Yeni ${ }^{3}$,Anita Trisiana ${ }^{4}$ \\ ${ }^{1}$ Mahasiswa PPKn Universitas Slamet Riyadi Surakarta \\ ${ }^{4}$ Dosen PPKn Universits Slamet Riyadi Surakarta
}

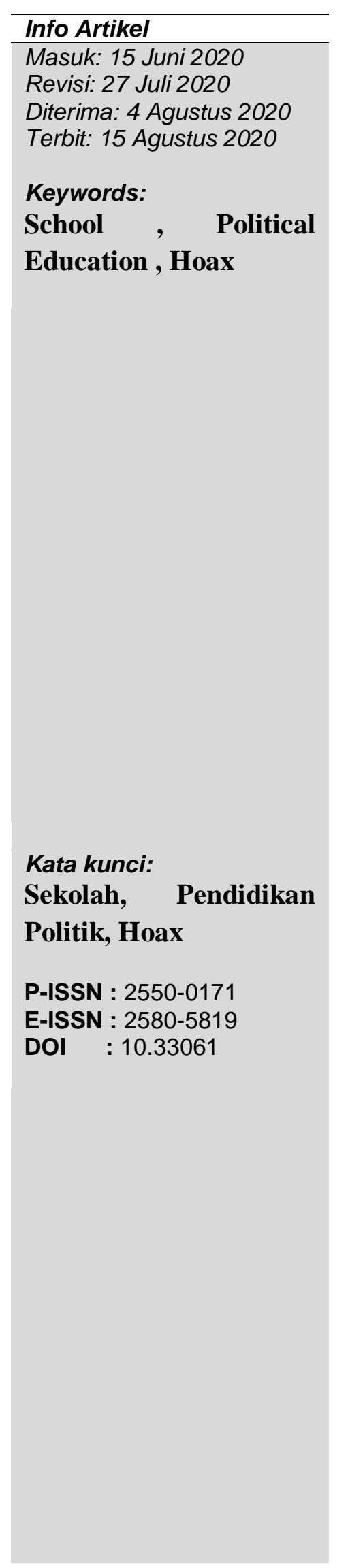

\begin{abstract}
The junior high school is an institution used for the activities of learn of teachers as well as the river subsides be left to be liberal and generous has so far obtained teaching subject corresponding to its field. School would be one of the places where to educate anak-anak with a view to give the science which is given to be they can be useful for a nation and country. This study aims to to see how the role of of the schools in political education. The fact that there are official middle east news agency hoax in indonesia quite disturbing and extremely dangerous for the community especially students of becoming professional actors, in order to do this schools are obliged to increase political awareness students. Was used in the study a method of descriptive of it is anticipated that analysis. The role of school showed that school is the role of most important education for made by media political education that can be educate political students via with the program political education both through subjects pkn, osis activities, extracurricular, and the form of other activities that planned manner and is open to give political information to students.
\end{abstract}

\section{Abstrak}

Sekolah adalah suatu lembaga yang digunakan untuk kegiatan belajar bagi para pendidik serta menjadi tempat memberi dan juga menerima pelajaran yang sesuai dengan bidangnya. Sekolah menjadi salah satu tempat untuk mendidik anak-anak dengan maksud untuk memberikan ilmu yang diberikan supaya mereka dapat berguna untuk bangsa dan negara. Penelitian ini bertujuan untuk melihat bagaimana peranan sekolah dalam pendidikan politik. Adanya berita hoax di Indonesia sangat meresahkan dan sangat berbahaya bagi masyarakat terutama pelajar, untuk itu sekolah wajib meningkatkan kesadaran politik siswa. Penelitian ini menggunakan metode deskriptif analisis. Peran sekolah menunjukan bahwa sekolah adalah peranan terpenting pendidikan untuk dijadikan media pendidikan politik yang dapat menanamkan kesadaran politik siswa melalui dengan program pendidikan politik baik melalui mata pelajaran $\mathrm{PKn}$, kegiatan OSIS, ekstrakurikuler, maupun bentuk kegiatan lain yang terencana dan bersifat terbuka untuk memberikan informasi politik kepada siswa. 


\section{PENDAHULUAN}

Teknologi komunikasi dan informasi (TIK) berkembang mengikuti perkembangan zaman dengan adanya beragam media termasuk media online. Kemudahan serta efisiensi yang ditawarkan media online dalam penggunaannya menjadikan media ini menjadi wadah penyebaran informasi yang sangat berpengaruh pada masyarakat. Media online tidak hanya mengubah cara penyampaian informasi tetapi juga mengubah cara masyarakat mengkonsumsi informasi. Sekolah adalah suatu lembaga yang digunakan untuk kegiatan belajar bagi para pendidik serta menjadi tempat memberi dan juga menerima pelajaran yang sesuai dengan bidangnya.

Sekolah menjadi salah satu tempat untuk mendidik anak-anak dengan maksud untuk memberikan ilmu yang diberikan supaya mereka dapat berguna untuk bangsa dan negara. Sekolah memiliki peran yang sangat penting bagi kehidupan bangsa. Yang memiliki fungsi mempersiapkan Peserta Didik Suatu Pekerjaan, memberikan ketrampilan dasar dan memberikan ketrampilan umum. David Easton (Sirozi, 2005: 49) mengatakan bahwa 'salah satu kondisifundamental untuk mempertahankan suatu system politik ialah ketika generasi muda di dalam masyarakat menginjak dewasa, harus menguasai ilmu-ilmu pengetahuan, nilai, sikap yang diharapkan oleh system yang ada. Pendidikan politik sangat berperan penting untuk dapat mendidik generasi muda agar mendapat ilmu pemahaman yang jelas dengan macam-macam symbol dan konsep tentang politik terutama membentuk kesadaran dalam berpolitik.

Masalah tentang informasi Hoax sudah bukan hal asing lagi bagi masyarakat di era modern seperti saat ini. Hoax ialah perbuatan melanggar hukum seperti penipuan, memfitnah suatu berita kepada pendengar, pembaca dan masyarakat. Hoax bertujuan merancang opini masyarakat, membuat persepsi yang bermacam-macam yang menguji tingkat kecerdasan pembaca terutama pengguna internet dan media sosial. Untuk itu diharapkan dengan adanya pendidikan politik, siswa mengerti dan paham untuk dapat memilih, memilah mana berita yang benar dan berita yang dibuatbuat. Dengan kata lain, pelajar yang belum mempunyai pengetahuan luas akan sangat rentan terpengaruh dan terjerumus terhadap berita hoax.

\section{METODE PENELITIAN}

Metode yang digunakan yaitu metode deskriptif. Menurut Nazir (1988:63) metode deskriptif : "Metode dalam meneliti status kelompok manusia, suatu objek, suatu kondisi, suatu system pemikiran maupun suatu kelas peristiwa pada masa sekarang. Dengan kata lain tujuan penelitian deskriptif yaitu membuat deskripsi secara sistematis, factual dan akurat mengenai fakta - fakta dan berhubungan antar fenomena yang diselidiki. Dikatakan deskriptif yaitu bertujuan memberikan analisis yang objektif mengenai peran sekolah dalam pendidikan politik mengkaji berita hoax.

\section{PEMBAHASAN}

Implementasi sekolah mengajarkan pendidikan politik dalam mengkaji berita hoax yaitu :

1. Pembelajaran PPKn

Pelaksanaan pembelajaran Pendidikan Pancasila dan Kewarganegaraan sangat penting dalam meningkatkan kesadaran politik siswa, karena jika didasarkan pada tujuannya, PPKn atau 
dalam istilah lain lebih dikenal sebagai civic education mempunyai fungsi dan peran sebagai pendidikan politik. Dalam kurikulum PPKn terdapat beberapa materi politik yang nantinya dengan penyampaian materi politik tersebut diharapkan akan memberikan pemahaman kepada siswa mengenai informasi politik yang dan benar termasuk berita Hoax, yang pada akhirnya dapat meningkatkan kesadaran politik siswa dan lebih jauhnya akan dapat mendorong siswa untuk ikut berperan serta dalam kegiatan politik dalam lingkup kecil seperti di sekolah maupun dalam lingkup yang luas yaitu di kehidupan bermasyarakat, berbangsa dan bernegara. Di sekolah pelaksanaan pendidikan politik utamanya dilakukan melalui mata pelajaran Pendidikan Pancasila dan Kewarganegaraan

\section{Program Kesiswaan}

Pelaksanaan pendidikan politik di sekolah selain melalui mata pelajaran PPKn juga dilakukan melalui program yang dibuat oleh bagian kesiswaan. Program kesiswaan yang ada sekolah diantaranya adalah program pengembangan diri melalui ekstra kurikuler, satuan tugas pelaksanaan kesiswaan, tata tertib dan disiplin, program sosialisasi dan program pembinaan OSIS. Yang amat sangat terkait dengan program pendidikan politik yaitu, program pembinaan OSIS dan kegiatan ekstra kulikuler. Dalam kegiatan OSIS yang menjadi poin penting pelaksanaan pendidikan politik yaitu bagaimana siswa belajar untuk berorganisasi. Adanya pembinaan OSIS yang dilaksanakan oleh pihak kesiswaan, telah menjadi bukti bahwa sekolah telah melaksanakan kegiatan dalam pendidikan politik di sekolah untuk siswanya. Pembinaan yang dilaksanakan terhadap OSIS akan memberikan mereka pengetahuan dan pengalaman mengenai kepemimpinan dan bagaimana cara menjalankan roda organisasi. Organisasi OSIS akan memberikan kesempatan kepada siswa untuk berperan serta dalam kegiatan politik di sekolah. Dalam kegiatan OSIS, ada beberapa hal yang menjadi bagian penting dari proses pendidikan politik yaitu adanya pemilihan OSIS secara langsung oleh warga sekolah yang dilaksanakan rutin setahun sekali dan kegiatan Latihan Dasar Kepemimpinan

Siswa (LDKS) yang bertujuan memberikan keterampilan kepemimpinan bagi siswa calon pengurus OSIS.

\section{Ektrakulikuler}

Adalah suatu kegiatan setelah jam pelajaran dilaksanakan di dalam maupun diluar area sekolah. Bertujuan memperdalam ilmu pengetahuan siswa dan dapat menyalurkan minat dan bakat siswa tersebut. Ekstrakulikuler memfasilitasi siswa mendapatkan pendidikan politik diantaranya yaitu pramuka, paskibra, ataupun PMR. Pelaksanaan pendidikan politik di sekolah dapat dilakukan dengan cara lain, semisal dengan membuat suatu kegiatan yang secara langsung memberikan informasi politik kepada siswa seperti dalam bentuk penyuluhan ataupun sosialisasi politik yang mengundang praktisi politik maupun pembicara yang ahli dibidang politik. Selain itu bisa juga pendidikan politik dilakukan melalui bentuk lain yaitu dengan menempelkan informasi politik seperti surat kabar atau majalah yang ditempel di papan pengumuman sekolah ataupun dalam majalah dinding. Dengan cara-cara itu lah siswa dapat memperoleh informasi pendidikan politik serta siswa dapat memilah berita yang benar dan yang salah(Hoax).

\section{Pendidikan Politik}


Pendidikan yaitu langkah merubah sikap perilaku seseorang menjadi benar dan menambah ilmu pengetahuan, pengalaman, secara terencana dan terus menerus menjadi manusia yang berbudi pekerti, dewasa yang dilandasi oleh ideologi, nilai dan budaya. Proses pendidikan tidak hanya dilakukan disekolah saja, tetapi bisa dilakukan di luar sekolah yaitu : dilingkungan masyarakat, pekerjaan dan keluarga. Dalam konteks Negara Kesatuan Republik Indonesia segala urusan yang berkenaan dengan negara harus berlandaskan ideologi dan pandangan hidup, yakni Pancasila.

Dengan demikian pendidikan politik ialah memdidik seseorang untuk merubah sikap dan perilaku individu dan bahkan masyarakat untuk memahami dan mengerti akan nilai yang terdapat dalam system politik yang benar yang diimplementasikan dilingkung masyarakat dan negara dimana mereka berada. Pendidikan Politik dapat memfokuskan terhadap masalah yang berkaitan dengan nilai moral dan etika, nilai keilmuan, nilai kemasyarakatan (kebangsaaan); d) organisasi kepemimpinan dan manajemen. Untuk mencapai tujuan itu diperlukan pendidikan, serta praktek langsung dalam berbagai aktivitas kemasyarakatan, kebangsaan dan politik kenegaraan. Salah satu pendidikan politik diwujudkan dalam bentuk pendidikan kewarganegaraan. Tujuan utama dari pendidikan kewarganegaraan ialah mendidik warga negara paham hak dan kewajiban masingmasing, patriotisme dan menjunjung tinggi asas kedaulatan serta persatuan dan kesatuan bangsa.

Pendidikan Kesadaran Bela Negara merupakan salah bagian dari pendidikan kewarganegaraan yang bertujuan untuk mengubah sikap dan perilaku warga negara yang memiliki kecintaan kepada tanah air, ikut berpatisipasi dimasyarakat dan bernegara, mempunyai keyakinan dan menjadikan Pancasila sebagai ideologi negara mempunyai rasa impati terhadap orang lain, dan sikap patriotisme teradap negara. Prilaku masyarakat yang paham dengan bela tanah air yaitu prasyarat dalam membangun sistem pertahanan rakyat semesta/sistem pertahanan keamanan rakyat semesta khsususnya dan menjaga kelangsungan hidup bangsa dan negara. Untuk membentuk sikap dan perilaku diperlukan pendidikan. Tujuan pendidikan pada umumnya ialah membimbing tiap individu didalam aspek pribadi, sosial dan moral yang berhubungan dengan sosiokutural. Oleh karena itu, proses pendidikan kesadaran bela negara harus dimulai dari lingkungan keluarga, sekolah/perguruan tinggi, dan masyarakat.

Pelaksanaan pendidikan dapat bersifat formal, sekolah, perguruan tinggi serta yang mempunyai kurikulum. Non formal (dengan kurikulum yang relatif lebih singkat dan sederhana dibandingkan dengan pendidikan formal, misalnya kursus, penataran dll), dan informal tanpa kurikulum misalnya pendidikan dikeluarga, masyarakat juga organisasi kemasyarakatan, serta contoh-contoh suritauladan dari pemimpin. Dengan pendidikan politik dapat memberikan tujuan dan cita-cita luhur nasional dan menumbuh kembangkan kesadaran akan cinta tanah air, kesadaran berbangsa dan bernegara, melaksanakan hak dan kewajiban masing-masing. 


\section{KESIMPULAN}

Sekolah adalah suatu lembaga yang digunakan untuk kegiatan belajar bagi para pendidik serta menjadi tempat memberi dan juga menerima pelajaran yang sesuai dengan bidangnya. Sekolah menjadi salah satu tempat untuk mendidik anak-anak dengan maksud untuk memberikan ilmu yang diberikan supaya mereka dapat berguna untuk bangsa dan negara. Sekolah memiliki peran yang sangat penting bagi kehidupan bangsa. Yang memiliki fungsi mempersiapkan Peserta Didik Suatu Pekerjaan, memberikan ketrampilan dasar dan memberikan ketrampilan umum. Selain memberikan pendidikan formal, sekolah menjadi peran utama siswa tentang pendidikan politik yang benar agar siswa tidak mudah percaya dengan berita-berita hoax dengan melalui pelajaran PPKn, program kesiswaan, dan ektrakulikuler. 


\section{DAFTAR PUSTAKA}

Amelia Haryati. 2016. Peran Dan Sikap Guru Dalam Mensosialisasiakan Pendidikan Politik Di Sekolah. Studi Politik, hal 70-85

Encep Syarief N. 2015. The Policies on Civic Education in Developing National Character in Indonesia, Politics \& Studi Vol 8 No 8

Lantip Diat P. 2012. Financial Resources Sebagai Faktor Penentu Dalam Implementasi Kebijakan Pendidikan. Studi, Vol 4 No 2

Miles, M.B. \& Huberman, A. M. 2007. Analisis Data Kualitatif: Buku Sumber tentang Metodemetode Baru. Terjemahan oleh Tjetjep Rohendi Rohidi dari judul Qualitative Data Anlysis. Jakarta: Universitas Indonesia Press.

Muhammad Sirozi. 2005. Politik pendidikan: Dinamika hubungan antara kepentingan kekuasaan dan praktik penyelenggaraan pendidikan. Raja Grafindo Persada.

Munchson AR. 2009. Media Kajian Kewarganegaraan, Jurnal Civics, Vol 6 No 1

Nur Kholik. 2017. Peranan Sekolah Sebagai Lembaga Pengembangan Pendidikan Multikultural. Jurnal Pendidikan, Vol 1 No 2

Strauss, A. \& Corbin, J. 2009. Dasar-dasar Penelitian Kualitatif: Tatalangkah dan Teknik-teknik Teoritisasi Data. Terjemahan oleh Muhammad Shodiq dan Imam Muttaqien dari judul Basics of Qualitative Research: Grounded Theory Procedures and Techniques. Yogyakarta: Pustaka Pelajar.

Sudijono Sastroatmodjo. 1995. Perilaku politik. Semarang: IKIP Press.

Hariyanti. 2014. Pendidikan Pemilih Sebagai Sumber Pembelajaran Pendidikan Kewarganegaraan Untuk Meningkatkan Partisipasi Politik Peserta Didik, hal 1-13 
